\title{
Clinical outcomes, not clinical utility, should be the major consideration for saxagliptin with or without metformin
}

This article was published in the following Dove Press journal:

Patient Preference and Adherence

15 April 2014

Number of times this article has been viewed

\section{Sheila A Doggrell}

Department of Pharmacology, School of Biomedical Sciences, Faculty of Health, Queensland University of Technology,

Brisbane, QLD, Australia
Correspondence: Sheila A Doggrell Department of Pharmacology, School of Biomedical Sciences, Faculty of Health, Queensland University of Technology, GPO 2434, Brisbane, QLD 4002, Australia Email sheila.doggrell@qut.edu.au

\section{Dear editor,}

A recent review by Panagoulias and Doupis, published in Patient Preference and Adherence, concerned the saxagliptin/metformin fixed combination (SAXA/MET FDC), and was titled "Clinical utility in the treatment of type 2 diabetes with the saxagliptin/metformin fixed combination." This review concluded that "The SAXA/MET FDC is a patient-friendly, dosage-flexible, and hypoglycemia-safe regimen with very few adverse events and a neutral or even favorable effect on body weight. It achieves significant glycosylated hemoglobin $\mathrm{A}_{1 \mathrm{c}}$ reduction helping the patient to achieve his/her individual glycemic goals."

Although these conclusions about saxagliptin are reasonable, in my opinion this review seems to have put too much emphasis on clinical utility and not enough emphasis on the clinical outcomes of cardiovascular safety and efficacy. For the subject with type 2 diabetes, the ultimate goal is to reduce cardiovascular outcomes, and in this, achieving glycemic control is just a surrogate endpoint. Metformin has been shown to improve cardiovascular outcomes in subjects with type 2 diabetes. However, saxagliptin alone, or in combination with metformin has not been shown to improve clinical outcomes.

For metformin, improved cardiovascular outcomes were shown in the UK Prospective Diabetes Study (UKPDS) 34..$^{2}$ In this study, 342 overweight subjects with type 2 diabetes were assigned intensive control treatment with metformin, which was $850 \mathrm{mg} /$ day, then $850 \mathrm{mg}$ twice daily, and $1,700 \mathrm{mg}$ in the morning followed by $850 \mathrm{mg}$ with the evening dose. Subjects were allowed to reduce their dose of metformin, if symptoms of diarrhea or nausea occurred. This intensive treatment with metformin was compared with the conventional treatment of diet. After about 10 years, subjects taking metformin had a 32\% reduction of developing any diabetes-related endpoint, which included macrovascular and microvascular complications, compared to subjects who were not treated with anti-diabetes drugs. ${ }^{2}$

Even for metformin, it is not clear whether the findings of UKPDS-34 apply to the dose and preparation of metformin being used in SAXA/MET FDC. Thus, the findings in UKPDS-34, with metformin, are with the conventional rather than the extended release preparation, and are only applicable to the dose used, which is not given. When metformin hydrochloride extended release is used alone, in Australia, the initial dose is $500 \mathrm{mg}$ once daily, which can be increased up to $2 \mathrm{~g}$. When metformin hydrochloride extended release is combined with saxagliptin, the doses available 
are 500,850 , or $1,000 \mathrm{mg} /$ day. Without testing of these doses of extended release metformin in clinical trial, it is not known whether they are high enough to have the clinical benefits observed in UKPDS-34. Thus, it cannot be assumed that the doses of metformin extended release, which have been combined with saxagliptin, are improving clinical outcomes.

Most trials with saxagliptin have been comparator trials with other anti-diabetes medicines with surrogate endpoints such as $\mathrm{HbA}_{1 \mathrm{c}}$. Similarly, surrogate endpoints have been the major outcomes for trials on saxagliptin as add-on or combination treatment with metformin. These trials are not discussed as they do not have clinical outcomes.

The only trial to determine cardiovascular endpoints with saxagliptin is the cardiac safety trial: SAVOR-TIMI 53 (Saxagliptin Assessment of Vascular Outcomes Recorded in Patients with Diabetes Mellitus-Thrombolysis in Myocardial Infarction 53 trial). In SAVOR-TIMI 53, saxagliptin 5 mg was compared to placebo, in subjects with type 2 diabetes, $70 \%$ of whom were taking metformin. ${ }^{3}$ At the time that the review by Panagoulias and Doupis went to press, the only information available, from SAVOR-TIMI 53, was a paragraph, from the company, ${ }^{4}$ and the supporting data were not supplied. This paragraph was paraphrased by Panagoulias and Doupis as "Preliminary data have shown that SAXA have met the primary safety objective of noninferiority; but did not meet the primary efficacy objective of superiority for a composite end point of cardiovascular death, nonfatal myocardial infarction, or nonfatal ischemic stroke, when added to the patient's current standard of care (with or without other antidiabetic therapies) compared to placebo."

SAVOR-TIMI 53 has recently been published in the New England Journal of Medicine, ${ }^{3}$ and the data supports the paragraph paraphrased above. However, analysis of the individual items in this trial show they were similar in saxagliptin $5 \mathrm{mg}$ and placebo group, except for hospitalization for heart failure, which was $27 \%$ higher in the saxagliptin group (3.5\%) than the placebo group
$(2.8 \%, P=0.007) .^{3}$ This is not mentioned in the company's web summary. ${ }^{4}$ A recent meta-analysis presented to the Australasian Society of Experimental and Clinical Pharmacologists and Toxicologists, reported that dipeptidyl peptidase-4 inhibitors had no effect on all-cause mortality, cardiovascular mortality, myocardial infarction, stroke, but significantly increased hospitalization for heart failure. ${ }^{5}$ Thus, the cardiovascular safety of saxagliptin and other dipeptidyl peptidase-4 inhibitors alone has not been established.

In conclusion, although clinical utility is important for medicines used in diabetes, it should not be forgotten that improved clinical outcomes are the ultimate goal. These have not been shown for saxagliptin alone, or in combination with metformin. It is also important to firmly establish the cardiovascular safety of saxagliptin, and this has not been achieved to date. In my opinion, these points should have been emphasized in the review by Panagoulias and Doupis. ${ }^{1}$

\section{Disclosure}

The author reports no conflicts of interest in this communication.

\section{References}

1. Panagoulias GS, Doupis J. Clinical utility in the treatment of type 2 diabetes with the saxagliptin/metformin fixed combination. Patient Prefer Adherence. 2014;8:227-236.

2. UK Prospective Diabetes Study (UKPDS) Group. Effect of intensive blood-glucose control with metformin on complications in overweight patients with type 2 diabetes (UKPDS 34). Lancet. 1998;352:854-865.

3. Scirica BM, Bhatt DL, Braunwald E, et al. Saxagliptin and cardiovascular outcomes in patients with type 2 diabetes mellitus. N Eng J Med. 2013; 369:1317-1326.

4. AstraZeneca and Bristol-Myers Squibb announce top line results for SAVOR-TIMI-53 cardiovascular outcomes trial of Onlyza ${ }^{\circledR}$ (saxagliptin). Available from: http://news.bms.com/pressrelease/astrazeneca-and-bristol-myers-squibb-announce-top-line-resultssavor-timi-53-cardiovas. Accessed February 18, 2014.

5. Wu S, Hopper I, Skiba M, Krum H. Dipeptidyl peptidase-inhibitors and cardiovascular outcomes: a meta-analysis of randomized clinical trials. Available from: http://www.asceptasm.com/wp-content/uploads/2013/06/ ASCEPT-abstracts-202-315.pdf. Accessed February 27, 2014. 


\section{Author's response John Doupis}

Diabetes Clinic, Salamis Naval Hospital, Athens, Greece; Diabetes Division, latriko Paleou, Falirou Medical Center, Athens, Greece

Correspondence: John Doupis

latriko Paleou Falirou Medical Center,

Diabetes Division, 36 Areos St,

I75 62 Paleou Falirou, Athens, Greece

$\mathrm{Tel} / \mathrm{Fax}+302109892300$

Email john.doupis@joslin.harvard.edu

\section{Dear editor,}

In response to the letter from Doggrell commenting on our recently authored paper titled "Clinical utility in the treatment of type 2 diabetes with the saxagliptin/metformin fixed combination," ${ }^{, 2}$ I completely agree with Doggrell that clinical outcomes should be the major consideration, not only for the treatment with saxagliptin or saxagliptin/metformin combination, but also for the treatment with other diabetes related oral or injectable agents. However, the aim of this review paper was to focus on "the clinical utility of the saxagliptin/metformin combination." It was an invited review paper, thus, we mainly focused on the requested topic which would actually fit better to the scope of the journal Patient Preference and Adherence.

Indeed, SAVOR-TIMI 53 (Saxagliptin Assessment of Vascular Outcomes Recorded in Patients with Diabetes Mellitus-Thrombolysis in Myocardial Infarction 53 trial) results had not yet been published by the time we finished our work and we thank Doggrell for pointing out the main points of this study. ${ }^{3}$ Relative to the topics addressed by Doggrell regarding cardiovascular safety of the DPP-4 inhibitors, I would like also to add, that proving cardiovascular safety does not necessarily mean that DPP-4 inhibitors provide cardiovascular protection as well. In the meta-analysis by Wu et al DPP-4 inhibitors did not provide cardiovascular protection, their use resulted in no effect on cardiovascular mortality, myocardial infarction and stroke. ${ }^{4}$ The increased rate of heart failure related hospitalization, along with the one reported for saxagliptin in the SAVOR-TIMI 53 trial, should be further investigated., To this direction, given that cardiac failure is a multifactorial condition, I believe, that more large and long-term prospective studies should be conducted in order to fully reveal the relationship between the cardiovascular system and the use of DPP-4 inhibitors.

\section{Disclosure}

The author reports no conflicts of interest in this communication.

\section{References}

1. Doggrell SA. Clinical outcomes, not clinical utility, should be the major consideration for saxagliptin with or without metformin. Patient Prefer Adherence. 2014;8:473-475.

2. Panagoulias GS, Doupis J. Clinical utility in the treatment of type 2 diabetes with the saxagliptin/metformin fixed combination. Patient Prefer Adherence. 2014;8:227-236.

3. Scirica BM, Bhatt DL, Braunwald E, et al. Saxagliptin and cardiovascular outcomes in patients with type 2 diabetes mellitus. $N$ Eng $J$ Med. 2013;369:1317-1326.

4. Wu S, Hopper I, Skiba M, Krum H. Dipeptidyl peptidase-inhibitors and cardiovascular outcomes: a meta-analysis of randomized clinical trials. Available from: http://www.asceptasm.com/wp-content/uploads/2013/06/ ASCEPT-abstracts-202-315.pdf. Accessed February 27, 2014.
Patient Preference and Adherence

\section{Publish your work in this journal}

Patient Preference and Adherence is an international, peer-reviewed, open access journal that focusing on the growing importance of patient preference and adherence throughout the therapeutic continuum. Patient satisfaction, acceptability, quality of life, compliance, persistence and their role in developing new therapeutic modalities and compounds to optimize

\section{Dovepress}

clinical outcomes for existing disease states are major areas of interest for the journal. This journal has been accepted for indexing on PubMed Central. The manuscript management system is completely online and includes a very quick and fair peer-review system, which is all easy to use. Visit http://www. dovepress.com/testimonials.php to read real quotes from published authors. 